\title{
PCDD/F Emission from Pharmaceutical Industries
}

\author{
Mingxiu Zhan ${ }^{1,2}$, Yufeng Ma ${ }^{1}$, Xiaoqing Lin ${ }^{1 *}$, Zhiliang Chen ${ }^{1}$, Tong Chen ${ }^{1}$, Xiaodong $\mathrm{Li}^{1}$, \\ Jianhua Yan $^{1}$ \\ ${ }^{1}$ State Key Laboratory for Clean Energy Utilization, Institute for Thermal Power Engineering, Zhejiang University, \\ Hangzhou 310027, China \\ ${ }^{2}$ College of Metrology and Measurement Engineering, China Jiliang University, Hangzhou 310018, China
}

\begin{abstract}
The emission levels and profiles of unintentionally formed polychlorinated dibenzo- $p$-dioxins/furans (PCDD/Fs) were comprehensively investigated in flue gases released from 16 regenerative thermal oxidizers (RTOs) belonging to 8 pharmaceutical industries (PIs) in China. The PCDD/F total concentrations and TEQ values with great variation, ranged from $0.148-9.051 \mathrm{ng} \mathrm{m}^{-3}$ and $0.008-0.255 \mathrm{ng} \mathrm{I-TEQ} \mathrm{m}^{-3}$, respectively. Emission levels of most RTOs were lower than the emission standard of China $\left(0.1 \mathrm{ng}\right.$ I-TEQ $\left.\mathrm{m}^{-3}\right)$, yet two were above $0.25 \mathrm{ng}$ I-TEQ $\mathrm{m}^{-3}$. The PCDD/F concentrations in flue gases were in the order of HWIs > MSWIs > PIs. OCDD was identified to be the dominant congener in most RTOs, accounting for 21-71 wt $\%$. In addition, 1,2,3,7,8-PeCDF, 2,3,4,7,8-PeCDF and 1,2,3,4,7,8-HxCDF were effective TEQ indicators, especially for $2,3,4,7,8-\mathrm{PeCDF}$ with a Pearson correlation coefficient of 0.995 . The estimated annual emission amount (AE) of PCDD/Fs for PIs in this study was in the range of $0.435-11.016 \mathrm{mg} \mathrm{I-TEQ} \mathrm{year}{ }^{-1}$, with an average of $2.65 \mathrm{mg}$ I-TEQ year ${ }^{-1}$. It was estimated that $19.96 \mathrm{~g} \mathrm{I}$-TEQ of PCDD/Fs were emitted from Chinese PIs to atmosphere in 2017. This is the first comprehensive investigation on the unintentional emissions of PCDD/Fs from PIs in China.
\end{abstract}

Keywords: Emission characteristics; PCDD/Fs; Annual emission (AE); Pharmaceutical industry (PI); Regenerative thermal oxidizer (RTO).

\section{INTRODUCTION}

Persistent organic pollutants (POPs) have received extensive attention for their high toxicities to environment and human. The Stockholm Convention on POPs, established by the United Nations Environment Program (UNEP), aims to minimize or eliminate both of the production and the use of POPs. Parties need to identify sources of POPs and to accurately compile lists of POPs emitted into the environment (Black et al., 2012). Polychlorinated dibenzo$p$-dioxins (PCDDs) and poly-chlorinated dibenzofurans (PCDFs) are formed unintentionally during chemical production and municipal solid waste incineration. PCDD/Fs as important components of POPs to which humans are exposed, have been proven to be carcinogenic, neurotoxic and immunotoxic (Tsai et al., 2014; Hsieh et al., 2018b; Hung et al., 2018). The Standardized Toolkit for Identification and Quantification of Dioxin and Furan Releases was first published in 2003 and was amended for the second time in 2013. The source categories listed in the Toolkit are divided

\footnotetext{
${ }^{*}$ Corresponding author.

E-mail address: linxiaoqing@zju.edu.cn
}

into ten groups (Waste Incineration, Ferrous and NonFerrous Metal Production, Heat and Power Generation, Production of Mineral Products, Transport, Open Burning Processes, Production and Use of Chemicals and Consumer Goods, Miscellaneous, Disposal and Landfill, and Contaminated Sites and Hotspots) and five release sectors (air, land, water, product, and residue) (UNEP, 2013). In addition, it provided a method of calculating annual emission for each source, with vector and recommended emission factors applied in these calculations. Due to limited published data, emission factors of PCDD/Fs in flue gas from pharmaceutical industries (PIs) have not been provided in the Toolkit so far.

With extensive attention on public health, pharmaceutical industry (PI) has experienced fast growth and now plays an important role in the national economy in China (MIIT, 2016). At present, Chinese pharmaceutical market is the second largest market in the world ( $\mathrm{Wu}$ and $\mathrm{Hsu}, 2018$ ), which however puts significant concern of organic pollutants (e.g., PCDD/Fs) emission from PIs. In fact, due to its rapid development and considerable pollution (Lin, 2011; Wang et al., 2011; Li et al., 2014), PI has been regarded as one of the 12 key industries in Chinese national environmental protection plan.

In addition, the pressure faced by the PI for 
environmental protection keeps increasing, especially with the employment of the Law Emission Standard of Air Pollutants for Pharmaceutical Industry Chemical Synthesis Products Category (DB33, 2016). The PI is one of the heavily polluting industries because a wide variety of hazardous chemicals are used as raw materials (Dos Santos and Biundo, 1999; Priya and Philip, 2015; Gao et al., 2019). In order to minimize or eliminate VOCs in exhaust gases, technologies such as chemical spray adsorption, plasma, biotrickling filtration, activated carbon adsorption, condensation, incineration, have been adopted by many PIs (Balasubramanian et al., 2012; Wu et al., 2015; Hu et al., 2016). Among them, incineration is widely used due to the high removal efficiency and long service life. Regenerative Thermal Oxidizer (RTO) is one of the incineration facilities. However, chlorine contained in exhaust gases can result in the formation of PCDD/Fs during incineration (Dyke et al., 2007; UNEP, 2013). There are many studies on the $\mathrm{PCDD} / \mathrm{Fs}$ emission in thermal processes such as waste incineration and steel industry (Kuo et al., 2011; Wang et al., 2014; Mubeen et al., 2017; Xu et al., 2018; Zhan et al., 2018). However, there are little or no researches on the emission of PCDD/Fs from the RTO in PIs. According to the statistics of the National Bureau of Statistics of China, the number of pharmaceutical manufacturing industry in China increased from 5,926 in 2011 to 7,532 in 2017, with a growth rate of $27 \%$ in five years (National Bureau of Statistics of China, 2017). It is clear that PI is a very important potential source for PCDD/F emission, and it is necessary to conduct a comprehensive study to identify the emission characteristics of PCDD/Fs from RTO, thus to provide basic data for controlling $\mathrm{PCDD} / \mathrm{Fs}$ from $\mathrm{PI}$ in future.

RTO has been widely applied for controlling VOCs with a heat recovery rate up to $95 \%$ (Bannai et al., 2006; Vij, 2006). The RTO system decomposes the organics in exhaust gases into carbon dioxide and water by high-temperature oxidation and then recovers the heat, thereby achieving the dual purposes of both environmental protection and energy conservation (Bannai et al., 2006; Chang and Chern, 2009). In RTO technology, from the perspective of energy saving, the exhaust gas is gradually preheated during the flow through the regenerative ceramic bed to the combustion chamber, and the operation output is maximized through a series of cyclic operations. In each cycle, VOC-contaminated gas flows through the hot bed (as a preheater) to increase its temperature, then completes oxidation in the combustion chamber and eventually releases most of its heat to the cold bed, which acts as a thermal energy storage device. High heat recovery reduces fuel requirements and saves operating costs (Amelio and Morrone, 2007). The reaction equation for the degradation of organic matters in the combustion chamber of RTO is as follows:

$\mathrm{C}_{x} \mathrm{H}_{y}+\left(x+\frac{y}{4}\right) \mathrm{O}_{2} \underset{700-900^{\circ} \mathrm{C}}{\longrightarrow} x \mathrm{CO}_{2}+\frac{y}{2} \mathrm{H}_{2} \mathrm{O}$

In order to update the Toolkit (2013 version), and to fill up the research gaps, this study aims to estimate annual emission amount base on investigating the emission levels and profiles of PCDD/Fs in flue gases released from eight typical pharmaceutical industries (PIs) in China. Principal component analysis (PCA) is utilized to analyze the differences and similarities between congener patterns of all samples. In addition, the correlations between TEQ and mass concentrations of $\mathrm{PCDD} / \mathrm{Fs}$ are examined by linear regression. This work will facilitate the management of $\mathrm{PCDD} / \mathrm{F}$ emissions from PIs and help to predict congener profiles and average concentrations.

\section{MATERIALS AND METHODS}

\section{Sample Collection}

The flue gas samples were collected from 16 facilities belonged to 8 pharmaceutical industries (PIs), and the information about facilities are shown in Table 1. All PIs are equipped with RTO to treat VOCs.

Flue gas samples were collected with isostack sampler (TCR TECORA, Italy) according to U.S. EPA Method 23a. The sampling box composed of a glass fiber filter, 5 impingers ( 1 silica gel, 2 empty, and 2 water) and a resin. The collection lasts $2-3 \mathrm{~h}$ for each sample according to the national standard coded as HJ 77.2-2008. Before sampling, the ${ }^{13} \mathrm{C} 12$-labelled EDF-4054 with $100 \mathrm{ng} \mathrm{mL}^{-1}$ in nonane as sampling standard was spiked to $\mathrm{XAD}-2$ resin. The EDF-4055 served as a recovery standard for PCDD/Fs, and ${ }^{13} \mathrm{C} 12$-labelled EDF-4053 served as extraction standard. Three parallel samples were collected for each point and the mean value was determined.

\section{Sample Analysis and Statistical Methods}

The flue gas samples were transferred to the Soxhlet to extract more than 16 hours together with ${ }^{13} \mathrm{C}_{12}$ labeled PCDD/Fs internal standard and toluene. Then the colored samples were washed repeatedly with sulfuric acid until transparent. The purification procedure for PCDD/Fs analysis was carried out using two columns, namely multi-layer silica gel column $(15 \mathrm{~mm}$ ID $\times 30 \mathrm{~cm}$, elution with $100 \mathrm{~mL}$ of n-hexane) and basic alumina column $(15 \mathrm{~mm} \mathrm{ID} \times 30 \mathrm{~cm}$, $1^{\text {st }}$ elution with $100 \mathrm{~mL}$ of $\mathrm{n}$-hexane and $2^{\text {nd }}$ elution with a 1:1 mixture of n-hexane and dichloromethane)

The purified extracts were detected by high-resolution gas chromatography and high-resolution mass spectrometry (HRGC/HRMS) interfaced with a 6890 Series gas chromatograph (Agilent, USA) coupled with a JMS-800D mass spectrometer (JEOL, Japan). A capillary column DB-5 ms $(60 \mathrm{~m} \times 0.25 \mathrm{~mm}$ I.D., $0.25 \mu \mathrm{m}$ film thickness $)$ was applied to separate the PCDD/F congeners. Samples were injected in a splitless mode at an injector temperature of $280^{\circ} \mathrm{C}$ and at an initial column temperature of $90^{\circ} \mathrm{C}$. The mean recoveries of the standards for $\mathrm{PCDD} / \mathrm{Fs}$ ranged from 65 to $120 \%$, which were within the acceptable range of $25-150 \%$. And all data were obtained in the selected ion monitoring (SIM) mode. The toxic equivalents (I-TEQ) values for PCDD/Fs were calculated by using international toxicity equivalency factor (ITEF). Statistical analyses of PCDD/Fs were carried out by IBM SPSS Statistics 
Table 1. Information of the investigated facilities in China.

\begin{tabular}{|c|c|c|c|c|c|}
\hline & $\begin{array}{l}\text { Combustion } \\
\text { temperature } \\
\left({ }^{\circ} \mathrm{C}\right)\end{array}$ & $\begin{array}{l}\text { Stack } \\
\text { temperature } \\
\left({ }^{\circ} \mathrm{C}\right)\end{array}$ & $\begin{array}{l}\text { Flue gas } \\
\text { rate } \\
\left(\mathrm{m}^{3} \mathrm{~h}^{-1}\right)\end{array}$ & Exhaust gas main components & APCDs \\
\hline R1 & $750-850$ & 65 & 12,100 & $\begin{array}{l}\text { Methanol, vinyl chloride, } \\
\text { isobutylene, phenols, ketones, etc. }\end{array}$ & Cooling tower + alkali scrubber \\
\hline $\mathrm{R} 2$ & $750-850$ & 66 & 12,400 & $\begin{array}{l}\text { Methanol, vinyl chloride, } \\
\text { isobutylene, phenols, ketones, etc. }\end{array}$ & Cooling tower + alkali scrubber \\
\hline R3 & $750-850$ & 65 & 16,000 & $\begin{array}{l}\text { Vinyl chloride, isobutylene, } \\
\text { phenols, ketones, etc. }\end{array}$ & Cooling tower + alkali scrubber \\
\hline R4 & $750-850$ & 68 & 15,000 & $\begin{array}{l}\text { Vinyl chloride, isobutylene, } \\
\text { phenols, ketones, etc. }\end{array}$ & Cooling tower + alkali scrubber \\
\hline R5 & $820-850$ & 75 & 13,100 & $\begin{array}{l}\text { Methanol, formaldehyde, cyanide, } \\
\text { isopropylene }\end{array}$ & Cooling tower + alkali scrubber \\
\hline R6 & $820-850$ & 75 & 13,200 & $\begin{array}{l}\text { Methanol, formaldehyde, cyanide, } \\
\text { isopropylene }\end{array}$ & Cooling tower + alkali scrubber \\
\hline R7 & $820-850$ & 76 & 11,100 & $\begin{array}{l}\text { Dichloromethane, acetone, } \\
\text { ethanol, ammonia }\end{array}$ & Cooling tower + alkali scrubber \\
\hline $\mathrm{R} 8$ & $820-850$ & 76 & 10,900 & $\begin{array}{l}\text { Dichloromethane, acetone, } \\
\text { ethanol, ammonia }\end{array}$ & Cooling tower + alkali scrubber \\
\hline R9 & $820-850$ & 74 & 11,200 & $\begin{array}{l}\text { Methanol, chlorine, formaldehyde, } \\
\text { methyl chloride }\end{array}$ & Cooling tower + alkali scrubber \\
\hline $\mathrm{R} 10$ & $820-850$ & 74 & 12,800 & $\begin{array}{l}\text { Methanol, chlorine, formaldehyde, } \\
\text { methyl chloride }\end{array}$ & Cooling tower + alkali scrubber \\
\hline R11 & $820-850$ & 72 & 10,800 & $\begin{array}{l}\text { Methanol, methyl chloride, } \\
\text { polychlorohexene }\end{array}$ & Cooling tower + alkali scrubber \\
\hline $\mathrm{R} 12$ & $820-850$ & 72 & 12600 & $\begin{array}{l}\text { Methanol, methyl chloride, } \\
\text { polychlorohexene }\end{array}$ & Cooling tower + alkali scrubber \\
\hline $\mathrm{R} 13$ & $820-850$ & 68 & 12,100 & $\begin{array}{l}\text { Methanol, formaldehyde, } \\
\text { dichloromethane }\end{array}$ & Cooling tower + alkali scrubber \\
\hline R14 & $900-1100$ & 140 & 16,000 & $\begin{array}{l}\mathrm{HCl} \text {, methanol, chlorine, } \\
\text { formaldehyde, triethylamine, } \\
\text { methyl chloride }\end{array}$ & $\begin{array}{l}\text { Cooling with deacidification } \\
\text { tower }+ \text { activated carbon with } \\
\text { fabric filter }\end{array}$ \\
\hline $\mathrm{R} 15$ & $800-900$ & 67 & 11,100 & $\begin{array}{l}\text { Chloroform, ether, ethanol, } \\
\text { dichloromethane, organic amine }\end{array}$ & Cooling tower + alkali scrubber \\
\hline R16 & $800-900$ & 67 & 10,800 & $\begin{array}{l}\text { Chloroform, ether, ethanol, } \\
\text { dichloromethane, organic amine }\end{array}$ & Cooling tower + alkali scrubber \\
\hline
\end{tabular}

(Version 24). The congener profiles were assessed by Principal component analysis (PCA) with results represented by scores and a loading plot.

\section{RESULTS AND DISCUSSION}

\section{Emission Levels of PCDD/Fs in Various RTOs}

The concentration and I-TEQ value of PCDD/Fs in flue gases of 16 RTOs are shown in Fig. 1 and are summarized in Table 2 in detail. The concentration range of PCDDs is $0.038-0.600 \mathrm{ng} \mathrm{m}^{-3}$, with an average of $0.227 \mathrm{ng} \mathrm{m}^{-3}$ and a medium value of $0.189 \mathrm{ng} \mathrm{m}^{-3}$, both of which are much lower than those of PCDFs (range of 0.073-1.390 $\mathrm{ng} \mathrm{m}^{-3}$, average value $0.370 \mathrm{ng} \mathrm{m}^{-3}$, medium value $0.220 \mathrm{ng} \mathrm{m}^{-3}$ ). The concentration of PCDD-homologues generally increases with the rising of their degree of chlorination, which is not the case of PCDF-homologues. The concentration range of $\mathrm{PCDD} / \mathrm{Fs}$ is $0.148-9.051 \mathrm{ng} \mathrm{m}^{-3}$, with an average of $0.563 \mathrm{ng} \mathrm{m}^{-3}$ and a medium value of $0.334 \mathrm{ng} \mathrm{m}^{-3}$, and the corresponding range of the I-TEQ value is $0.008-0.255$

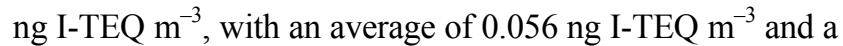
medium value of $0.055 \mathrm{ng}$ I-TEQ $\mathrm{m}^{-3}$. The average I-TEQ of PCDD/Fs from this study is several orders of magnitude lower than values reported from secondary zinc production in Vietnam (3.440 $\mathrm{ng}$ I-TEQ $\mathrm{m}^{-3}$ ) and from municipal solid waste incineration in China $\left(0.228 \mathrm{ng}^{\mathrm{I}-T E Q ~ \mathrm{~m}^{-3}}\right)$ ( $\mathrm{Li}$ et al., 2017; Pham et al., 2019), and is the same order of magnitude as those from municipal solid waste incineration in northern China (Zhu et al., 2018). Fourteen RTOs show emissions below the current PCDD/F emission standard for pharmaceutical industry chemical synthesis products category in China $\left(0.1 \mathrm{ng}\right.$ I-TEQ $\left.\mathrm{m}^{-3}\right)(\mathrm{DB} 33,2016)$. But for two RTOs (i.e., R15 and R16), the I-TEQ concentration of PCDD/Fs in flue gases is 0.249 and $0.255 \mathrm{ng} \mathrm{I-TEQ}^{-3}$, respectively, which are much higher than emission standard. The wide range of $\mathrm{PCDD} / \mathrm{Fs}$ in flue gases indicates the necessity of special attentions for pollution control. Application of flue gas purification systems usually exhibits acceptable effect for reduction of $\mathrm{PCDD} / \mathrm{F}$ emission. Activated carbon injection coupled with baghouse filters 
(a)

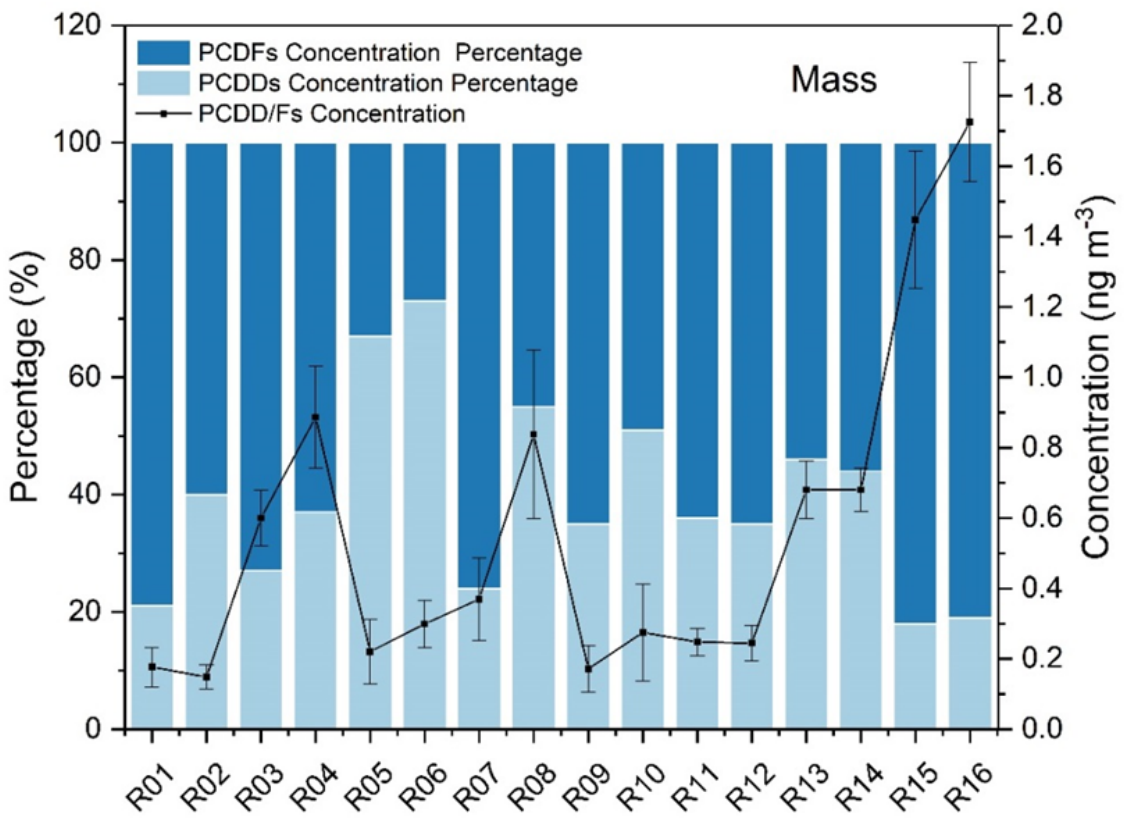

(b)

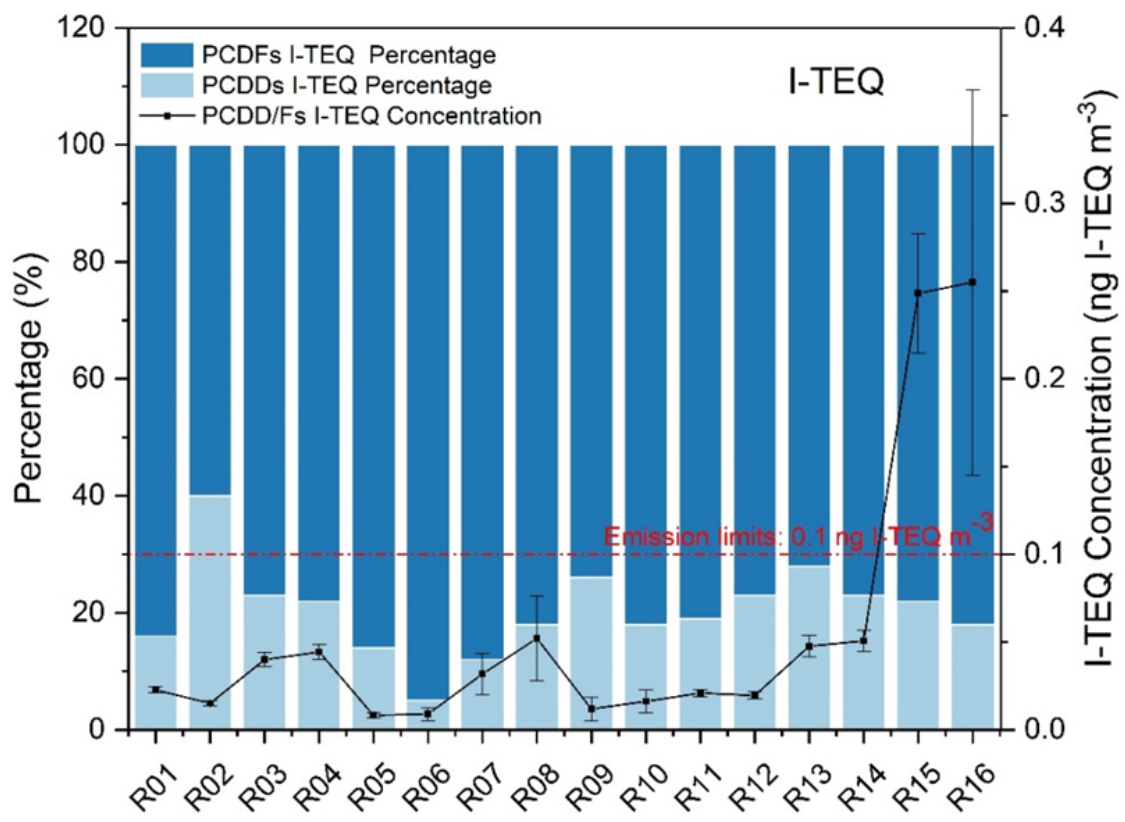

Fig. 1. (a) Mass and (b) I-TEQ concentration of PCDD/Fs in the flue gas of 16 RTOs.

are effective for PCDD/Fs control (Hung et al., 2011). Due to the low temperature of flue gases in R05 and R06 (Table 1), activated carbon injection coupled with baghouse filter can efficiently reduce the discharge of PCDD/Fs after the flue gases are reheated.

Considering the great variation of PCDD/F concentrations in flue gases, the average is not enough to represent the emission levels of PCDD/Fs from PIs, MSWIs and HWIs in China. Fig. 2 demonstrates some statistical parameters for flue gas samples from PIs, MSWIs and HWIs in China. The MSWIs and HWIs data are from the studies of Gao et al. (2009) and Zhu et al. (2018). The figure shows that the average value of PIs is higher than that of MSWIs, but the percentile 50 for PIs is lower than the percentile 25 for
MSWIs, indicating that PIs are generally characterized by lower emission levels than MSWIs in china. It is obvious that the percentile 25 for HWIs is much higher than the percentile 75 for either PIs or MSWIs. Therefore, the concentration of PCDD/Fs in flue gas is in the order of HWIs $>$ MSWIs $>$ PIs.

\section{Congener Profiles of PCDD/Fs in Flue Gases}

The PCDF/PCDD weight ratio is usually applied to roughly distinguish the major formation pathway of PCDD/Fs as: de novo synthesis $(\mathrm{PCDF} / \mathrm{PCDD}>1)$ or precursor formation (PCDF/PCDD < 1) (Luijk et al., 1994; Ni et al., 2009; Zhao et al., 2017). As shown in Fig. 1 (Mass), the proportion of PCDF in 12 RTOs flue gases marks much 
Table 2. Concentration and distribution of seventeen 2,3,7,8-substituted PCDD/Fs in flue gases of the 16 RTOs.

\begin{tabular}{|c|c|c|c|c|c|c|c|c|c|}
\hline & R01 & R02 & R03 & R04 & R05 & R06 & R07 & R08 & unit \\
\hline TCDD & 0.002 & 0.002 & 0.004 & 0.004 & 0.001 & 0.000 & 0.001 & 0.001 & $\mathrm{ng} \mathrm{m}^{-3}$ \\
\hline PeCDD & 0.003 & 0.005 & 0.005 & 0.006 & 0.001 & 0.000 & 0.002 & 0.004 & $\mathrm{ng} \mathrm{m}^{-3}$ \\
\hline HxCDD & 0.005 & 0.011 & 0.027 & 0.020 & 0.002 & 0.001 & 0.015 & 0.026 & $\mathrm{ng} \mathrm{m}^{-3}$ \\
\hline HpCDD & 0.009 & 0.014 & 0.067 & 0.048 & 0.005 & 0.003 & 0.023 & 0.041 & $\mathrm{ng} \mathrm{m}^{-3}$ \\
\hline OCDD & 0.019 & 0.027 & 0.056 & 0.250 & 0.140 & 0.214 & 0.049 & 0.388 & $\mathrm{ng} \mathrm{m}^{-3}$ \\
\hline$\Sigma$ PCDDs & 0.038 & 0.059 & 0.160 & 0.328 & 0.148 & 0.218 & 0.089 & 0.460 & $\mathrm{ng} \mathrm{m}^{-3}$ \\
\hline TCDF & 0.045 & 0.012 & 0.023 & 0.014 & 0.003 & 0.002 & 0.004 & 0.004 & $\mathrm{ng} \mathrm{m}^{-3}$ \\
\hline PeCDF & 0.045 & 0.020 & 0.049 & 0.053 & 0.011 & 0.011 & 0.033 & 0.047 & $\mathrm{ng} \mathrm{m}^{-3}$ \\
\hline $\mathrm{HxCDF}$ & 0.032 & 0.028 & 0.157 & 0.156 & 0.042 & 0.057 & 0.145 & 0.206 & $\mathrm{ng} \mathrm{m}^{-3}$ \\
\hline $\mathrm{HpCDF}$ & 0.012 & 0.018 & 0.162 & 0.147 & 0.010 & 0.007 & 0.077 & 0.107 & $\mathrm{ng} \mathrm{m}^{-3}$ \\
\hline OCDF & 0.005 & 0.011 & 0.050 & 0.190 & 0.007 & 0.005 & 0.021 & 0.013 & $\mathrm{ng} \mathrm{m}^{-3}$ \\
\hline$\Sigma$ PCDFs & 0.140 & 0.089 & 0.440 & 0.559 & 0.073 & 0.081 & 0.280 & 0.378 & $\mathrm{ng} \mathrm{m}^{-3}$ \\
\hline$\Sigma \mathrm{PCDD} / \mathrm{Fs}$ & 0.177 & 0.148 & 0.600 & 0.887 & 0.221 & 0.299 & 0.369 & 0.838 & $\mathrm{ng} \mathrm{m}^{-3}$ \\
\hline $\mathrm{PCDF} / \mathrm{PCDD}^{\mathrm{a}}$ & 3.7 & 1.5 & 2.8 & 1.7 & 0.5 & 0.4 & 3.1 & 0.8 & 1 \\
\hline $\mathrm{PCDF} / \mathrm{PCDD}^{\mathrm{b}}$ & 5.1 & 1.5 & 3.3 & 3.6 & 6.1 & 18.1 & 7.6 & 5.7 & l \\
\hline $\mathrm{Cl}-\mathrm{PCDD} / \mathrm{Fs}^{\mathrm{c}}$ & 5.6 & 6.4 & 6.6 & 7.1 & 7.3 & 7.4 & 6.5 & 7.1 & / \\
\hline \multirow[t]{2}{*}{ I-TEQ } & 0.023 & 0.015 & 0.040 & 0.044 & 0.008 & 0.009 & 0.032 & 0.052 & $\mathrm{ng}$ I-TEQ $\mathrm{m}^{-3}$ \\
\hline & R09 & $\mathrm{R} 10$ & R11 & $\mathrm{R} 12$ & R13 & $\mathrm{R} 14$ & $\mathrm{R} 15$ & $\mathrm{R} 16$ & unit \\
\hline TCDD & 0.001 & 0.001 & 0.001 & 0.001 & 0.003 & 0.002 & 0.011 & 0.013 & $\mathrm{ng} \mathrm{m}^{-3}$ \\
\hline PeCDD & 0.001 & 0.001 & 0.003 & 0.004 & 0.007 & 0.008 & 0.068 & 0.044 & $\mathrm{ng} \mathrm{m}^{-3}$ \\
\hline HxCDD & 0.007 & 0.006 & 0.009 & 0.011 & 0.050 & 0.044 & 0.086 & 0.087 & $\mathrm{ng} \mathrm{m}^{-3}$ \\
\hline HpCDD & 0.016 & 0.012 & 0.014 & 0.017 & 0.138 & 0.099 & 0.081 & 0.119 & $\mathrm{ng} \mathrm{m}^{-3}$ \\
\hline OCDD & 0.035 & 0.120 & 0.061 & 0.053 & 0.112 & 0.145 & 0.024 & 0.072 & $\mathrm{ng} \mathrm{m}^{-3}$ \\
\hline$\Sigma$ PCDDs & 0.600 & 0.141 & 0.089 & 0.086 & 0.311 & 0.298 & 0.270 & 0.335 & $\mathrm{ng} \mathrm{m}^{-3}$ \\
\hline TCDF & 0.002 & 0.003 & 0.010 & 0.014 & 0.018 & 0.015 & 0.218 & 0.202 & $\mathrm{ng} \mathrm{m}^{-3}$ \\
\hline PeCDF & 0.012 & 0.016 & 0.029 & 0.031 & 0.047 & 0.058 & 0.435 & 0.436 & $\mathrm{ng} \mathrm{m}^{-3}$ \\
\hline $\mathrm{HxCDF}$ & 0.051 & 0.078 & 0.076 & 0.049 & 0.159 & 0.169 & 0.440 & 0.523 & $\mathrm{ng} \mathrm{m}^{-3}$ \\
\hline $\mathrm{HpCDF}$ & 0.026 & 0.022 & 0.028 & 0.030 & 0.119 & 0.110 & 0.077 & 0.206 & $\mathrm{ng} \mathrm{m}^{-3}$ \\
\hline OCDF & 0.021 & 0.015 & 0.017 & 0.035 & 0.027 & 0.031 & 0.007 & 0.025 & $\mathrm{ng} \mathrm{m}^{-3}$ \\
\hline$\Sigma$ PCDFs & 0.111 & 0.135 & 0.159 & 0.156 & 0.370 & 0.382 & 1.178 & 1.390 & $\mathrm{ng} \mathrm{m}^{-3}$ \\
\hline$\Sigma \mathrm{PCDD} / \mathrm{Fs}$ & 0.172 & 0.275 & 0.248 & 0.245 & 0.681 & 0.681 & 1.448 & 1.726 & $\mathrm{ng} \mathrm{m}^{-3}$ \\
\hline $\mathrm{PCDF} / \mathrm{PCDD}^{\mathrm{a}}$ & 1.8 & 1.0 & 1.8 & 1.8 & 1.2 & 1.3 & 4.4 & 4.1 & / \\
\hline $\mathrm{PCDF} / \mathrm{PCDD}^{\mathrm{b}}$ & 3.9 & 4.6 & 4.3 & 3.4 & 2.6 & 3.3 & 3.5 & 4.7 & / \\
\hline $\mathrm{Cl}-\mathrm{PCDD} / \mathrm{Fs}^{\mathrm{c}}$ & 6.8 & 7.0 & 6.6 & 6.6 & 6.6 & 6.7 & 5.5 & 5.8 & / \\
\hline I-TEQ & 0.012 & 0.016 & 0.021 & 0.020 & 0.048 & 0.051 & 0.249 & 0.255 & ng I-TEQ $\mathrm{m}^{-3}$ \\
\hline
\end{tabular}

${ }^{\mathrm{a}}$ The concentration ratio of PCDF to PCDD.

$\mathrm{b}$ The I-TEQ ratio of PCDF to PCDD.

${ }^{\mathrm{c}}$ Weight average chlorination level was calculated as follows:

$\mathrm{Cl}=\frac{\sum C_{j} \times n_{j}}{C}(j=4,5,6,7,8)$

where $C_{j}$ is the concentration of each 2,3,7,8-substituted PCDD/Fs, $n_{j}$ is the amount of chlorine atom of each 2,3,7,8substituted PCDD/Fs; $\mathrm{C}$ is the total concentration of PCDD/Fs.

higher than that of PCDD $(\mathrm{R} 13>\mathrm{R} 14>\mathrm{R} 02>\mathrm{R} 04>\mathrm{R} 11$ $>\mathrm{R} 12>\mathrm{R} 09>\mathrm{R} 03>\mathrm{R} 07>\mathrm{R} 01>\mathrm{R} 16>\mathrm{R} 15>55 \%$ ), partially indicating de novo synthesis as the main pathway for PCDD/F formation in these RTOs. The proportion of PCDF and PCDD is similar in R08 and R10, indicating that de novo synthesis and precursor formation have the similar contribution on the formation of PCDD/F. For R05 and R06, the proportion of PCDD is much higher than that of PCDF (R06 > R05 > 55\%), indicating that the precursor formation is the major pathway for $\mathrm{PCDD} / \mathrm{F}$ formation in these two RTOs. In terms of I-TEQ concentration, the proportion of PCDF much higher than that of PCDD as in Fig. 1 (I-TEQ), indicating that PCDF is the main contributor to TEQ value in all RTOs flue gases. The detailed congener profiles of PCDD/Fs in flue gases are presented in Fig. 4 (Mass) and Fig. 5 (I-TEQ).

As a multivariate statistical method, principal component analysis (PCA) is frequently used in environmental science to reduce the dimensionality of a data set. PCA is commonly applied to analyze the similarities and differences between 


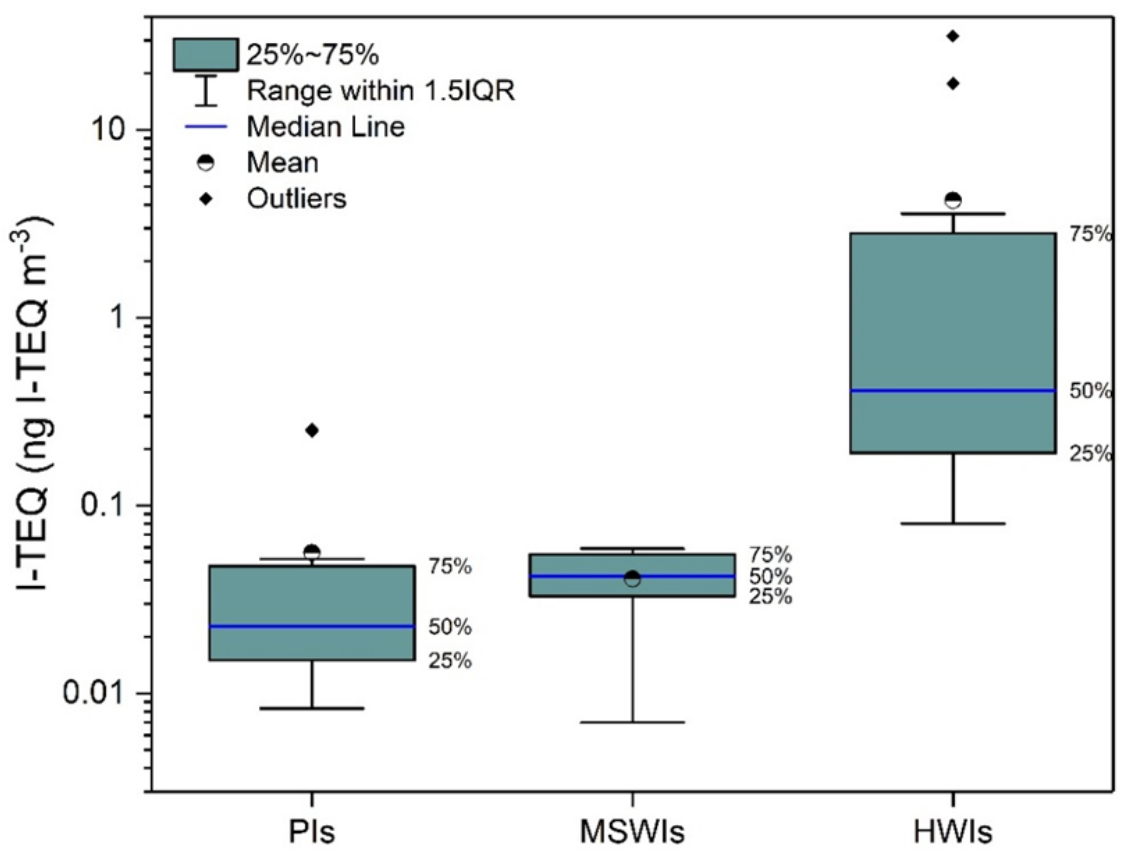

Fig. 2. PCDD/Fs statistical results of flue gas samples from PIs, MSWIs (Gao et al., 2009) and HWIs (Zhu et al., 2018) in China.

distribution patterns of PCDD/Fs for flue gas samples in all facilities, and to reveal the sources of PCDD/Fs (Fiedler et al., 1996; Gao et al., 2009; Jin et al., 2009; Liu and Liu, 2009). In the present study, this method is adopted to get a better understanding of PCDD/F-congener distributions from RTOs in China. PCA was performed on standardized PCDD/F-congeners data using IBM SPSS Statistics (Version 24). The score plot of PCA presenting the relative contributions of seventeen 2,3,7,8-substituted congeners is demonstrated in Fig. 3. The first principal component (PC1) accounts for $62.26 \%$ of the total variance, and the second principal component (PC2) accounts for $17.39 \%$ of the total variance. The score plot of PCA indicates that all of the investigated RTOs can be divided into three groups, and most RTOs belong to Group 3. PCDD/Fs in Group 3, including R04, R05, R06, R08, R09, R10, R11, R12 and $\mathrm{R} 14$, are strongly associated with $\mathrm{PC} 1$ derived from the correlative matrix. R01, R15 and R16 in Group 1 are associated with $\mathrm{PC} 2$ derived from another kind of matrix. For Group 2 involving R02, R03, R07 and R13 is associated with both PC1 and PC2, which might be due to the different distribution patterns of PCDD/Fs.

Congener profiles of each group are showed in Fig. 4. For Group 1, 2,3,4,7,8-PeCDF, 1,2,3,7,8-PeCDF and $2,3,7,8-\mathrm{TCDF}$ are three most abundant congeners (accounting for 51, 45 and $38 \%$ in R01, R15 and R16, respectively), indicating that high-chlorinated PCDFs are less than the low-chlorinated PCDFs. This result is different from that from municipal solid waste incinerators (Choi et al., 2008), but is similar to the results of Group 3 in the report of (Ni et al., 2009) and that of G33 in the report of (Yoon et al., 2017), who studied the PCDD/F emission in flue gases from municipal solid waste and medical waste incinerators, respectively. R15 and R16 with high emission of $0.25 \mathrm{ng}$ I-TEQ $\mathrm{m}^{-3}$ belong to Group 1. Congener 2,3,4,7,8-TCDF is the most abundant one (16 and $15 \%$ ) in these two RTOs, which is similar to the results of (Hoyos et al., 2008), who investigated the emission of $\mathrm{PCDD} / \mathrm{Fs}$ from medical waste incinerators in Antioquia. For Group 2, 1,2,3,4,6,7,8-HpCDF, 2,3,4,6,7,8-HxCDF, OCDD and 1,2,3,4,6,7,8-HpCDD are four most abundant congeners (accounting for 51, 52, 55 and $60 \%$ in R02, $\mathrm{R} 03, \mathrm{R} 07$ and R13, respectively), which is similar to the results of Group 2 in the report of (Ni et al., 2009) and that of Group 3 in the report of (Gao et al., 2009), who studied the $\mathrm{PCDD} / \mathrm{F}$ emission in flue gases from municipal solid waste and hospital waste incinerators. The distribution of other congeners is uniform. 9 out of 16 RTOs belong to Group 3, and OCDD is the most abundant congener (21$71 \%$ ), which is similar to the result of Group 1 in the report of (Gao et al., 2009). Most samples in this paper fall into same group, indicating that the congener profiles of PCDD/Fs are less influenced by the types of exhaust gases and APCDs. Some scholars believe that the chlorine concentration plays a significant role in deciding the formation mechanisms and congener profiles of PCDD/Fs in flue gases (Wang et al., 2003). When the chorine concentration is higher than a threshold, $\mathrm{PCDD} / \mathrm{Fs}$ are formed from PAHs through de novo synthesis, and the formation rates of PCDFs exceed those of PCDDs. When the chorine concentration is lower than a threshold, the chlorine is used to form chlorophenols, which are primary precursors of PCDD/Fs and produce much more PCDDs than PCDFs (Wilhelm et al., 2001; Wang et al., 2003; Ryu and Mulholland, 2005). In this study, (Table 1) the content of chlorine in the exhaust gases treated by R05 and R06 is less than that of the other facilities. This is the main reason that the proportion of PCDD exceeds $60 \%$. 


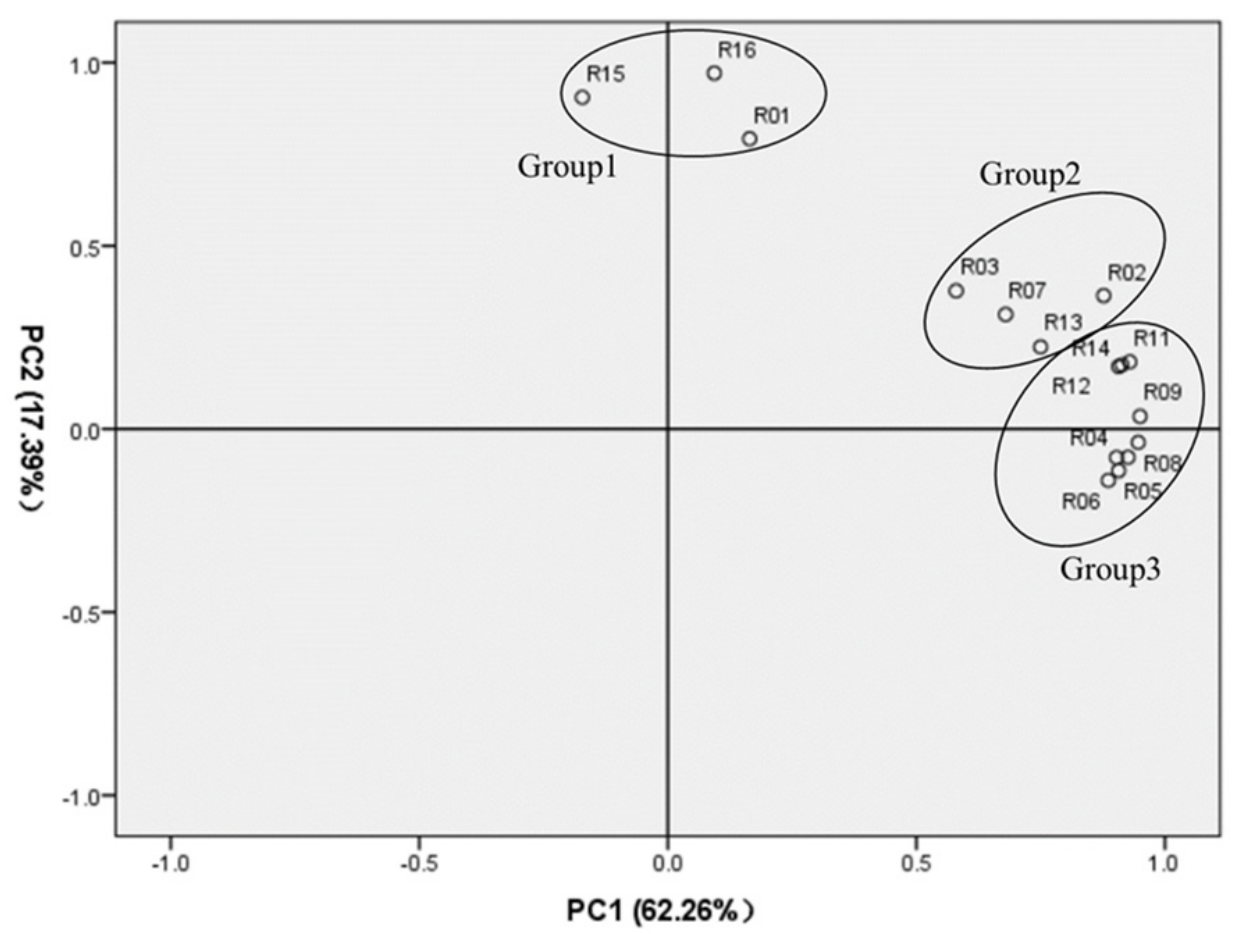

Fig. 3. Score plot of principal component analysis of seventeen 2,3,7,8-subsituteds-PCDD/F emissions.

The I-TEQ congener profiles are presented in Fig. 5. Except for R05 and R06, 2,3,4,7,8-PeCDF is the largest contributor for I-TEQ for other 14 RTOs, accounting for 27-50\%. Li et al. (2017) and Hsieh et al. (2018a) also found that 2,3,4,7,8-PeCDF was the biggest contributor in MSWIs and MWIs, suggesting that it should be regarded as a major factor for PCDD/Fs control. For R05 and R06, the largest contributor for I-TEQ is $1,2,3,6,7,8-\mathrm{HxCDF}$ (accounting for 31 and 40\%, respectively), followed by 2,3,4,7,8-PeCDF (accounting for 27 and 24\%, respectively). This is because that $1,2,3,6,7,8-\mathrm{HxCDF}$ is the second abundant congener with relatively high TEF of 0.1 .

\section{Correlations between TEQ and Congeners}

TEQ indicators have been widely applied for the realtime monitoring of PCDD/F emissions in MSWIs (Liu et al., 2013). Thus, linear regression is performed to examine the correlations between TEQ and mass concentrations of $\mathrm{PCDD} / \mathrm{F}$-congeners in flue gases of PIs, and the results are shown in Table 3 . The results present positive correlations $\left(\mathrm{R}^{2}>0.5\right)$ between TEQ and 12 congeners except for 1,2,3,4,6,7,8-HpCDD, OCDD, 1,2,3,4,6,7,8-HpCDF, $1,2,3,4,7,8,9-\mathrm{HpCDF}$ and OCDF. Three PCDD/Fs congeners (1,2,3,7,8-PeCDF, 2,3,4,7,8-PeCDF and 1,2,3,4,7,8-HxCDF) exhibits high correlation with TEQ with $\mathrm{R}^{2}$ of $0.970,0.995$ and 0.977 , respectively. This suggests that these three congeners could be regarded as TEQ indicators and applied for real-time monitoring of $\mathrm{PCDD} / \mathrm{F}$ emissions from $\mathrm{PIs}$ (Fig. 6), especially for 2,3,4,7,8-PeCDF $\left(\mathrm{R}^{2}=0.995\right)$. Also, the strong correlation between the concentration of 2,3,4,7,8-PeCDF and the I-TEQ value has been revealed by (Fiedler et al., 2010). Besides, TEQ indicators of municipal solid waste incineration (MSWI) and medical waste incineration (MWI) were analyzed by (Li et al., 2017; Zhu et al., 2018), indicating that OCDF and 1,2,3,4,7,8,9HpCDF were effective indicators in flue gas of MSWI plants, while 1,2,3,7,8,9-HxCDF and 1,2,3,4,7,8-HxCDF were effective indicators for MWI plants.

\section{Estimated Annual Emission Amount of PCDD/Fs}

A large number of researchers in recent years have estimated annual emissions (AE) of PCDD/Fs from thermal industrial processes, such as woodchip boilers (Bai et al., 2017), MSWIs and MWIs (Gao et al., 2009; Li et al., 2017), cement kilns (Conesa et al., 2016; Zou et al., 2018), metallurgical plants (Hu et al., 2013), etc. But there are few reports on the annual emissions of $\mathrm{PCDD} / \mathrm{Fs}$ in the PI and the current (UNEP, 2013) PCDD/F inventory toolkit also does not introduce PI sources. Therefore, the annual emission of PCDD/Fs obtained in this study would be a useful supplement for inventory toolkit of PCDD/Fs.

The formula for calculating the $\mathrm{AE}$ of $\mathrm{PCDD} / \mathrm{Fs}$ is:

$\mathrm{AE}=\mathrm{C} \times \mathrm{GF} \times \mathrm{OT} \times \mathrm{n} \times 10^{-9}$

where AE is annual emissions ( $\mathrm{g}$ I-TEQ year $^{-1}$ ), $\mathrm{C}$ is the TEQ concentration of PCDD/Fs in flue gas (ng I-TEQ $\mathrm{m}^{-3}$ ) GF is the flue gas flowrate $\left(\mathrm{m}^{3} \mathrm{~h}^{-1}\right)$, OT is the average operating time $\left(4000 \mathrm{~h} \mathrm{year}{ }^{-1}\right)$, and $\mathrm{n}$ is the estimated number of RTOs in China.

In this study, the annual emissions of $\mathrm{PCDD} / \mathrm{Fs}$ from flue gases of 16 RTOs are shown in Table 4. The annual emission of 16 RTOs ranges from 0.435 to $11.016 \mathrm{mg} \mathrm{I}$-TEQ year $^{-1}$, with a mean value of $2.65 \mathrm{mg}$ I-TEQ year ${ }^{-1}$. About 7532 Pharmaceutical manufacturing enterprises are recorded in China in 2017 (National Bureau of Statistics of China, 2017). 

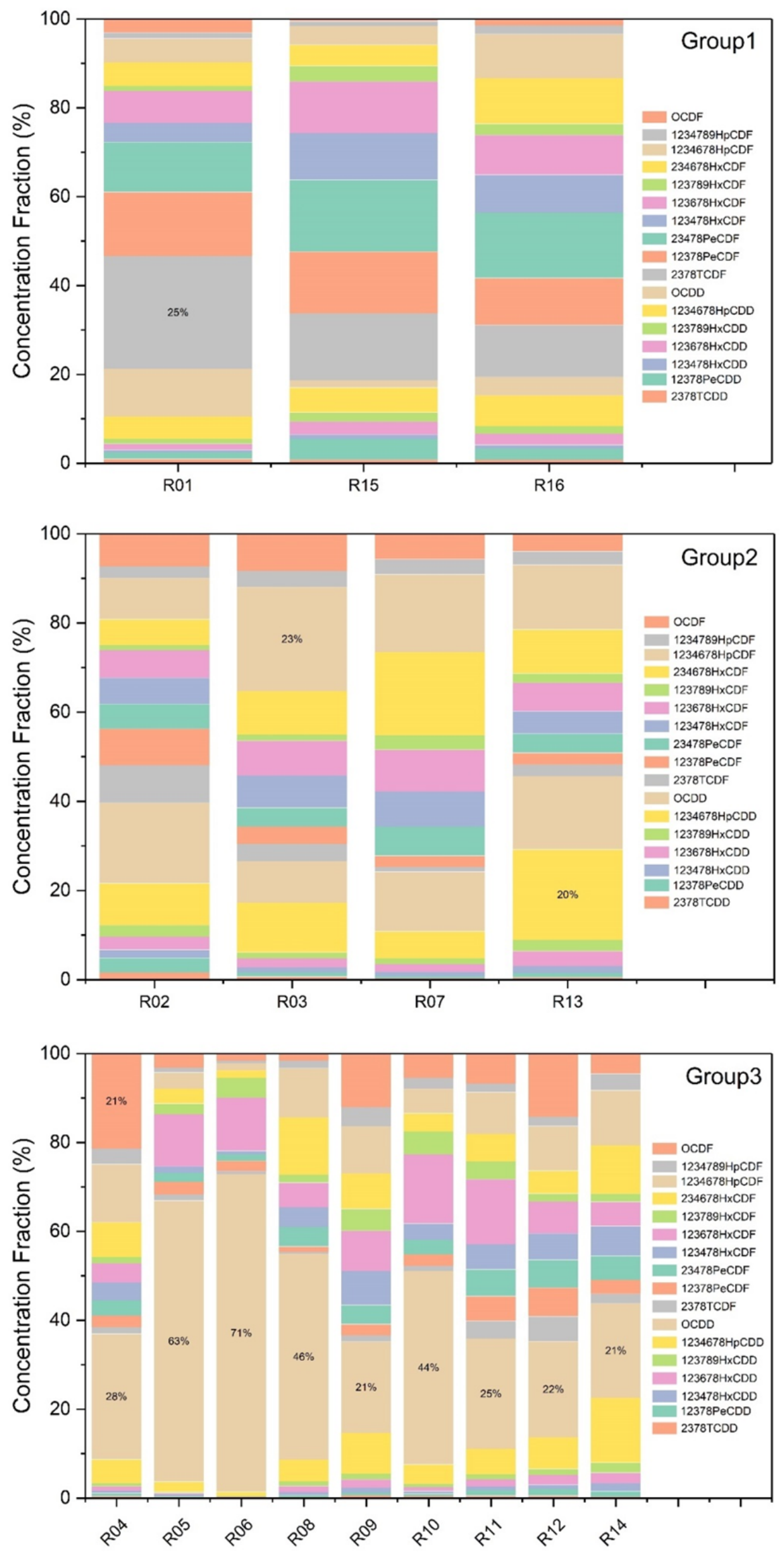

Fig. 4. Mass of seventeen 2,3,7,8-subsituteds-PCDD/Fs congeners profile in flue gas of three groups. 


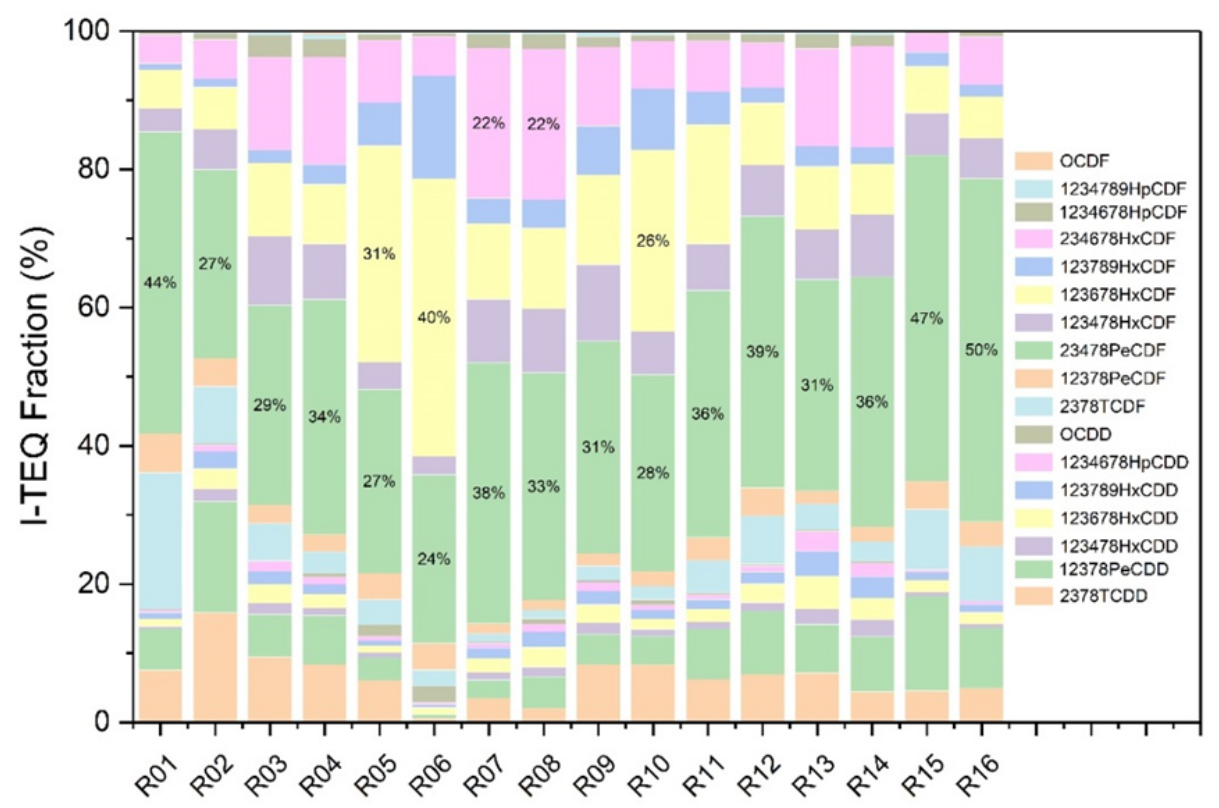

Fig. 5. TEQ of seventeen 2,3,7,8-subsituteds-PCDD/Fs congeners profile in flue gas from 16 RTOs.

Table 3. Correlations between TEQ and PCDD/Fs.

\begin{tabular}{lll}
\hline PCDD/Fs congeners & Regression equation & $\mathrm{R}^{2}$ \\
\hline $2,3,7,8-\mathrm{TCDD}$ & $18.63034 \mathrm{x}+0.01272$ & 0.56589 \\
$1,2,3,7,8-\mathrm{PeCDD}$ & $4.0266 \mathrm{x}+0.01504$ & 0.92624 \\
$1,2,3,4,7,8-\mathrm{HxCDD}$ & $12.78202 \mathrm{x}-0.01182$ & 0.65924 \\
$1,2,3,6,7,8-\mathrm{HxCDD}$ & $5.51695 \mathrm{x}-0.00846$ & 0.91304 \\
$1,2,3,7,8,9-\mathrm{HxCDD}$ & $7.58613 \mathrm{x}-0.00929$ & 0.86372 \\
$1,2,3,4,6,7,8-\mathrm{HpCDD}$ & $1.11029 \mathrm{x}+0.0069$ & 0.38919 \\
OCDD & $-0.11872 \mathrm{x}+0.06894$ & 0.02346 \\
$2,3,7,8-\mathrm{TCDF}$ & $1.11006 \mathrm{x}+0.01506$ & 0.94922 \\
$1,2,3,7,8-\mathrm{PeCDF}$ & $1.25572 \mathrm{x}+0.01039$ & 0.97041 \\
$2,3,4,7,8-\mathrm{PeCDF}$ & $1.00197 \mathrm{x}+0.00865$ & 0.99527 \\
$1,2,3,4,7,8-\mathrm{HxCDF}$ & $1.66566 \mathrm{x}-0.00659$ & 0.97707 \\
$1,2,3,6,7,8-\mathrm{HxCDF}$ & $1.65907 \mathrm{x}-0.02333$ & 0.95116 \\
$1,2,3,7,8,9-\mathrm{HxCDF}$ & $5.42991 \mathrm{x}-0.02187$ & 0.91635 \\
$2,3,4,6,7,8-\mathrm{HxCDF}$ & $1.18787 \mathrm{x}-0.00165$ & 0.52623 \\
$1,2,3,4,6,7,8-\mathrm{HpCDF}$ & $0.82586 \mathrm{x}+0.00683$ & 0.31612 \\
$1,2,3,4,7,8,9-\mathrm{HpCDF}$ & $4.15231 \mathrm{x}+0.00143$ & 0.31969 \\
OCDF & $-0.06918 \mathrm{x}+0.05793$ & 0.00154 \\
\hline
\end{tabular}

With an average annual emission of $2.65 \mathrm{mg} \mathrm{I}^{-T E Q}$ year ${ }^{-1}$, it is estimated that $19.96 \mathrm{~g} \mathrm{I}-\mathrm{TEQ}$ of PCDD/Fs is discharged to atmosphere in 2017 in China. The annual emission amount of $\mathrm{PCDD} / \mathrm{F}$ is larger than that from MSWIs in 2015 in China (14.58 g I-TEQ) (Zhu et al., 2018). However, the calculated mean value in this study is not enough to reflect emission amount exactly because of the limited data. More emission data from PIs are required to evaluate the potential emission amount of PCDD/Fs from PI in China in future.

\section{CONCLUSIONS}

This is the first study to comprehensively characterize $\mathrm{PCDD} / \mathrm{F}$ emissions in flue gases from 16 RTOs belonged to 8 pharmaceutical industries (PIs) in China. The emission concentration of $\mathrm{PCDD} / \mathrm{Fs}$ ranges from 0.148 to $9.051 \mathrm{ng} \mathrm{m}^{-3}$ and the TEQ ranges from 0.008 to $0.255 \mathrm{ng} \mathrm{I}^{-T E Q ~ \mathrm{~m}^{-3}}$, with a large variation. The emissions from 14 out of 16 RTOs are lower than the new standard in China $\left(0.1 \mathrm{ng} \mathrm{I}^{-T E Q ~ \mathrm{~m}^{-3}}\right)$. But the emissions from the other two RTOs are higher than the standard, indicating that incineration technologies of pharmaceutical industry ought to be further enhanced. The concentration of PCDD/Fs in flue gases are in the order of HWIs $>$ MSWIs $>$ PIs. Base on PCA results, 16 RTOs could be divided into three groups, and 9 out of 16 belong to Groups 3. OCDD (21-71\%) is the most abundant congeners in this group. R15 and R16 belonging to Group 1 have emissions above $0.25 \mathrm{ng}$ I-TEQ $\mathrm{m}^{-3}$, and are characterized as high content of 2,3,4,7,8-PeCDF (15 and 16\%). 
(a)

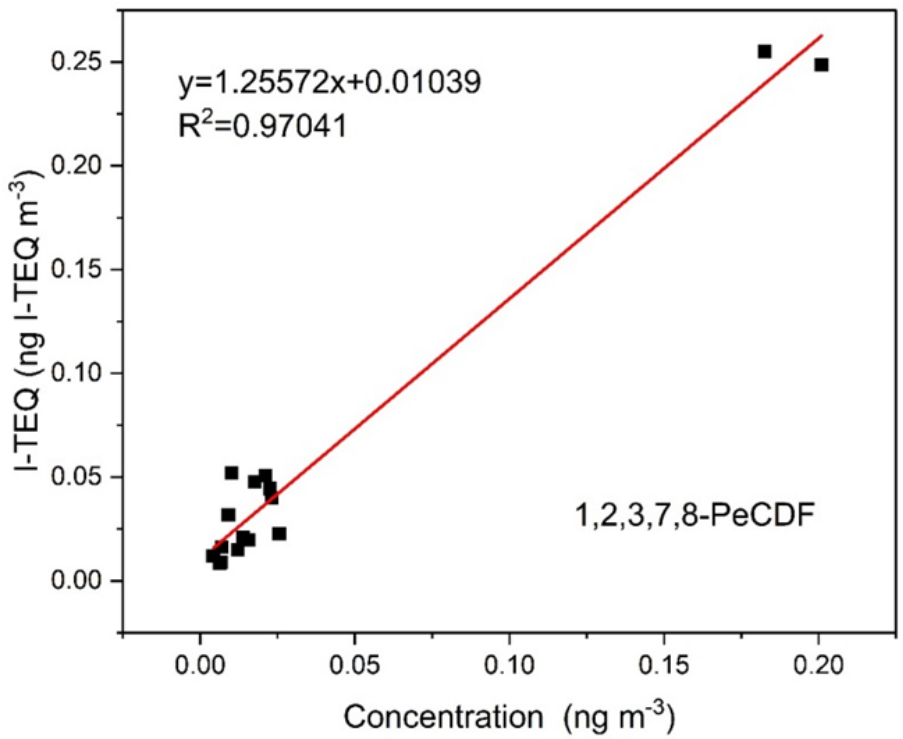

(b)

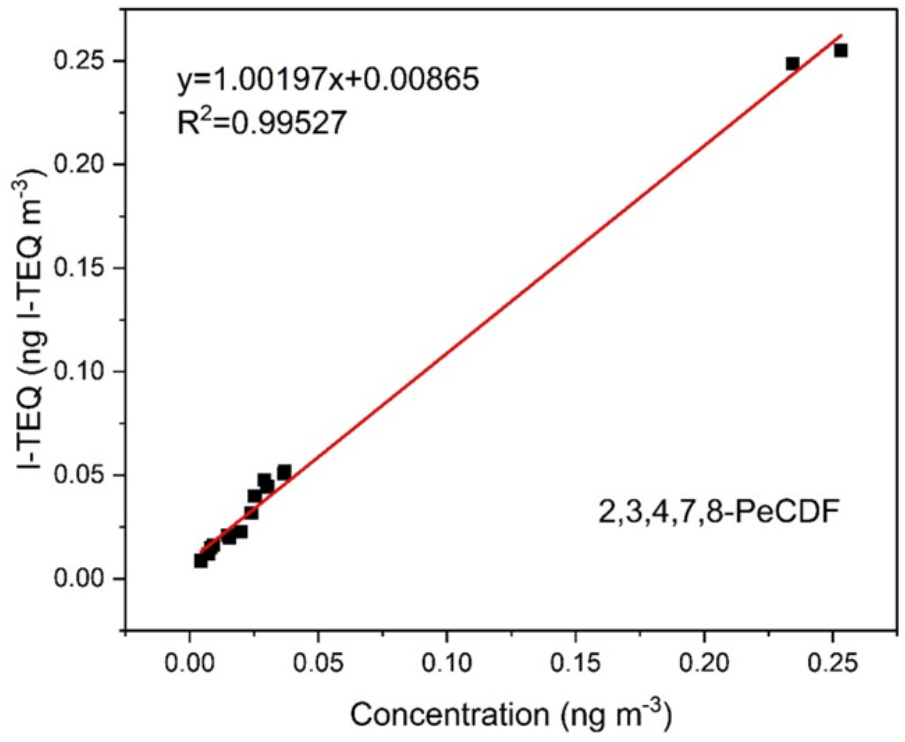

(c)

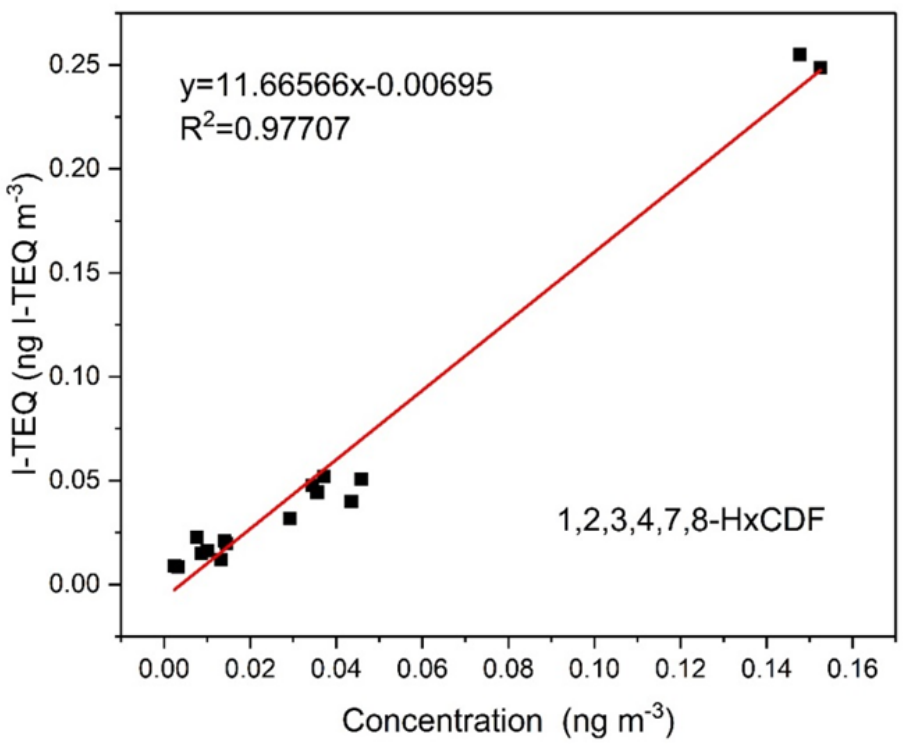

Fig. 6. Correlations between TEQ and three PCDD/Fs congeners (a, b, and c). 
Table 4. Annual emission amount of PCDD/Fs from 16 RTOs in China.

\begin{tabular}{lll}
\hline Facilities & $\begin{array}{l}\text { TEQ } \\
\left(\text { ng I-TEQ } ~^{-3}\right)\end{array}$ & $\begin{array}{l}\text { AE } \\
\left(\mathrm{mg} \mathrm{I}^{-T E Q ~} \text { year }^{-1}\right)\end{array}$ \\
\hline R01 & 0.023 & 1.126 \\
R02 & 0.015 & 0.726 \\
R03 & 0.040 & 2.554 \\
R04 & 0.044 & 3.161 \\
R05 & 0.008 & 0.435 \\
R06 & 0.009 & 0.470 \\
R07 & 0.032 & 1.386 \\
R08 & 0.052 & 2.309 \\
R09 & 0.012 & 0.533 \\
R10 & 0.016 & 0.701 \\
R11 & 0.021 & 1.071 \\
R12 & 0.020 & 0.988 \\
R13 & 0.048 & 2.307 \\
R14 & 0.051 & 4.056 \\
R15 & 0.249 & 10.943 \\
R16 & 0.255 & 11.016 \\
\hline
\end{tabular}

1,2,3,7,8-PeCDF, 2,3,4,7,8-PeCDF and 1,2,3,4,7,8-HxCDF are effective TEQ indicators, especially for 2,3,4,7,8-PeCDF with $\mathrm{R}^{2}$ of 0.995 . The estimated annual emission amount (AE) of PCDD/Fs are in the range of 0.435 to $11.016 \mathrm{mg} \mathrm{I-}$ TEQ year ${ }^{-1}$, with a mean value of $2.65 \mathrm{mg} \mathrm{I-TEQ} \mathrm{year}{ }^{-1}$. It is estimated that $19.96 \mathrm{~g} \mathrm{I-TEQ}$ of PCDD/Fs is discharged to atmosphere in 2017 in China.

\section{ACKNOWLEDGEMENTS}

This study was supported by the national key research and development program of China (2018YFB0605200), China Postdoctoral Science Foundation (2018M642429), the National Natural Science Foundation of China (51621005 and 51706201) and the Fundamental Research Funds for the Central Universities (2019FZA4010).

\section{REFERENCES}

Amelio, M. and Morrone, P. (2007). Numerical evaluation of the energetic performances of structured and random packed beds in regenerative thermal oxidizers. Appl. Therm. Eng. 27: 762-770.

Bai, S.T., Chang, S.H., Duh, J.M., Sung, F.H., Su, J.S. and Chang, M.B. (2017). Characterization of PCDD/Fs and dioxin-like PCBs emitted from two woodchip boilers in Taiwan. Chemosphere 189: 284-290.

Balasubramanian, P., Philip, L. and Murty Bhallamudi, S. (2012). Biotrickling filtration of VOC emissions from pharmaceutical industries. Chem. Eng. J. 209: 102-112.

Bannai, M., Houkabe, A., Furukawa, M., Kashiwagi, T., Akisawa, A., Yoshida, T. and Yamada, H. (2006). Development of efficiency-enhanced cogeneration system utilizing high-temperature exhaust-gas from a regenerative thermal oxidizer for waste volatile-organic-compound gases. Appl. Energy 83: 929-942.

Black, R.R., Meyer, C.P., Touati, A., Gullett, B.K., Fiedler,
H. and Mueller, J.F. (2012). Emission factors for $\mathrm{PCDD} / \mathrm{PCDF}$ and dl-PCB from open burning of biomass. Environ. Int. 38: 62-66.

Chang, M.W. and Chern, J.M. (2009). Stripping of organic compounds from wastewater as an auxiliary fuel of regenerative thermal oxidizer. J. Hazard. Mater. 167, 553-559.

Choi, K.I., Lee, S.H. and Lee, D.H. (2008). Emissions of PCDDs/DFs and dioxin-like PCBs from small waste incinerators in Korea. Atmos. Environ. 42: 940-948.

Conesa, J.A., Ortuño, N., Abad, E. and Rivera-Austrui, J. (2016). Emissions of PCDD/Fs, PBDD/Fs, dioxin likePCBs and PAHs from a cement plant using a long-term monitoring system. Sci. Total Environ. 571: 435-443.

DB33 (2016). Emission standard of air pollutants for pharmaceutical industry Chemical synthesis products category. Zhejiang Provincial People's Government.

Dos Santos, L.M.F. and Biundo, G.L. (1999). Treatment of pharmaceutical industry process wastewater using the extractive membrane bioreactor. Environ. Prog. 18: 34 39.

Dyke, P.H., Sutton, M., Wood, D. and Marshall, J. (2007). Investigations on the effect of chlorine in lubricating oil and the presence of a diesel oxidation catalyst on $\mathrm{PCDD} / \mathrm{F}$ releases from an internal combustion engine. Chemosphere 67: 1275-1286.

Fiedler, H., Lau, C., Kjeller, L.O. and Rappe, C. (1996). Patterns and sources of polychlorinated dibenzo- $p$ dioxins and dibenzofurans found in soil and sediment samples in Southern Mississippi. Chemosphere 32: 421432.

Fiedler, H., Lau, C. and Eduljee, G. (2010). Statistical analysis of patterns of PCDDs and PCDFs in stack emission samples and identification of a marker congener. Waste Manage. Res. 18: 283-292.

Gao, H., Ni, Y., Zhang, H., Zhao, L., Zhang, N., Zhang, X., Zhang, Q. and Chen, J. (2009). Stack gas emissions of $\mathrm{PCDD} / \mathrm{Fs}$ from hospital waste incinerators in China. Chemosphere 77: 634-639.

Gao, Z., Geng, Y., Wu, R., Chen, W., Wu, F. and Tian, X. (2019). Analysis of energy-related $\mathrm{CO}_{2}$ emissions in China's pharmaceutical industry and its driving forces. $J$. Cleaner Prod. 223: 94-108.

Hoyos, A., Cobo, M., Aristizábal, B., Córdoba, F. and Montes de Correa, C. (2008). Total suspended particulate (TSP), polychlorinated dibenzodioxin (PCDD) and polychlorinated dibenzofuran (PCDF) emissions from medical waste incinerators in Antioquia, Colombia. Chemosphere 73: S137-S142.

Hsieh, Y.K., Chen, W.S., Zhu, J. and Huang, Q. (2018a). Characterization of polychlorinated dibenzo- $p$-dioxins and dibenzofurans of the flue gases, fly ash and bottom ash in a municipal solid waste incinerator. Aerosol Air Qual. Res. 18: 421-432.

Hsieh, Y.K., Chen, W.S., Zhu, J., Wu, Y.J. and Huang, Q. (2018b). Health risk assessment and correlation analysis on PCDD/FS in the fly ash from a municipal solid waste incineration plant. Aerosol Air Qual. Res. 18: 734-748.

Hu, J., Zheng, M., Nie, Z., Liu, W., Liu, G., Zhang, B. and 
Xiao, K. (2013). Polychlorinated dibenzo- $p$-dioxin and dibenzofuran and polychlorinated biphenyl emissions from different smelting stages in secondary copper metallurgy. Chemosphere 90: 89-94.

Hu, J., Zhang, L., Chen, J., Luo, Y., Sun, B. and Chu, G. (2016). Performance and microbial analysis of a biotrickling filter inoculated by a specific bacteria consortium for removal of a simulated mixture of pharmaceutical volatile organic compounds. Chem. Eng. J. 304: 757-765.

Hung, N.T., Ting, H.W., and Chi, K.H. (2018). Evaluation of the relative health risk impact of atmospheric PCDD/Fs in $\mathrm{PM}_{2.5}$ in Taiwan. Aerosol Air Qual. Res. 18: 2591-2599.

Hung, P.C., Lo, W.C., Chi, K.H., Chang, S.H. and Chang, M.B. (2011). Reduction of dioxin emission by a multilayer reactor with bead-shaped activated carbon in simulated gas stream and real flue gas of a sinter plant. Chemosphere 82: 72-77.

Jin, G.Z., Lee, S.J., Park, H., Lee, J.E., Shin, S.K. and Chang, Y.S. (2009). Characteristics and emission factors of PCDD/Fs in various industrial wastes in South Korea. Chemosphere 75: 1226-1231.

Kuo, Y.C., Chen, Y.C., Yang, C.W., Mou, J.L., Shih, T.S. and Tsai, P.J. (2011). Identification the content of the windbox dust related to the formation of PCDD/Fs during the iron ore sintering process. Aerosol Air Qual. Res. 11: 351-359.

Li, J., Li, X., Lv, Z., Du, L., Hu, X., Wang, C., Niu, Z. and Zhang, Y. (2017). Emission characteristic of polychlorinated dibenzo- $p$-dioxins and polychlorinated dibenzofurans (PCDD/Fs) from medical waste incinerators (MWIs) in China in 2016: A comparison between higher emission levels of MWIs and lower emission levels of MWIs. Environ. Pollut. 221: 437444.

Li, Y., Wang, Z.M., Song, S., Xu, Z.R., Xu, M.Z. and Xu, W.L. (2014). Emission characteristics and hazard assessment analysis of volatile organic compounds from chemical synthesis pharmaceutical industry. Huan jing ke xue 35: 3663-3668.

Lin, J. (2011). Low-carbon transition of chinese pharmaceutical industry. Chin. J. Pharm. 42: 799-801.

Liu, J. and Liu, W. (2009). Distribution of polychlorinated dibenzo- $p$-dioxins and dibenzofurans (PCDDs/Fs) and dioxin-like polychlorinated biphenyls (dioxin-like PCBs) in the soil in a typical area of eastern China. J. Hazard. Mater. 163: 959-966.

Liu, W., Tian, Z., Li, H., Xie, H., Xiao, K., Li, C., Tang, C. and Zheng, M. (2013). Mono- to Octa-chlorinated $\mathrm{PCDD} / \mathrm{Fs}$ in stack gas from typical waste incinerators and their implications on emission. Environ. Sci. Technol. 47: 9774-9780.

Luijk, R., Akkerman, D.M., Slot, P., Olie, K. and Kapteijn, F. (1994). Mechanism of formation of polychlorinated dibenzo- $p$-dioxins and dibenzofurans in the catalyzed combustion of carbon. Environ. Sci. Technol. 28: 312321.

MIIT (2016). Guideline for pharmaceutical industry development plan.

Mubeen, I., Lin, X., Buekens, A., Cao, X., Lu, S., Tang, M. and Yan, J. (2017). PCDD/F formation in milled fly ash: Metal chloride catalysis. Aerosol Air Qual. Res. 17: 2858-2866.

National Bureau of Statistics of China (2017). China statistical yearbook. http://data.stats.gov.cn/easyquery.ht $\mathrm{m} ? \mathrm{cn}=\mathrm{C} 01 \& \mathrm{zb}=\mathrm{A} 0 \mathrm{~N} 0 \mathrm{Q} 01 \& \mathrm{sj}=2017$.

Ni, Y., Zhang, H., Fan, S., Zhang, X., Zhang, Q. and Chen, J. (2009). Emissions of PCDD/Fs from municipal solid waste incinerators in China. Chemosphere 75: 11531158.

Pham, M.T.N., Anh, H.Q., Nghiem, X.T., Tu, B.M., Dao, T.N. and Nguyen, M.H. (2019). Characterization of PCDD/Fs and dioxin-like PCBs in flue gas from thermal industrial processes in Vietnam: A comprehensive investigation on emission profiles and levels. Chemosphere 225: 238-246.

Priya, V.S. and Philip, L. (2015). Treatment of volatile organic compounds in pharmaceutical wastewater using submerged aerated biological filter. Chem. Eng. J. 266: 309-319.

Ryu, J.Y. and Mulholland, J.A. (2005). Metal-mediated chlorinated dibenzo- $p$-dioxin (CDD) and dibenzofuran (CDF) formation from phenols. Chemosphere 58: $977-$ 988.

Tsai, Y.A., Mao, I.F., Chi, K.H., Chang, M.B., Feng, C.C., Lin, C.H., Hung, P.C. and Chen, M.L. (2014). Health risk from exposure to $\mathrm{PCDD} / \mathrm{Fs}$ from a waelz plant in Central Taiwan. Aerosol Air Qual. Res. 14: 1310-1319.

UNEP (2013). Standardized toolkit for identification and quantification of dioxin and furan release. UNEP Chemicals, Geneva.

Vij, A. (2006). A primer on damper technologies for regenerative thermal oxidizers. Understanding the multiple functions that valves serve in common RTO systems. Met. Finish. 104: 17-22.

Wang, J., Zhao, R., Qin, Y. and Hui, L. (2011). Study on ecological construction of pharmaceutical industry cluster based on low carbon economy. Eco. Manage. 2011: 41-445.

Wang, L.C., Lee, W.J., Lee, W.S., Chang-Chien, G.P. and Tsai, P.J. (2003). Effect of chlorine content in feeding wastes of incineration on the emission of polychlorinated dibenzo-p-dioxins/dibenzofurans. Sci. Total Environ. 302: 185-198.

Wang, Q., Jin, Y., Li, X., Chen, J., Lu, S., Chen, T., Yan, J., Zhou, M. and Wang, H. (2014). PCDD/F emissions from hazardous waste incinerators in China. Aerosol Air Qual. Res. 14: 1152-1159.

Wilhelm, J., Stieglitz, L., Dinjus, E. and Will, R. (2001). Mechanistic studies on the role of PAHs and related compounds in PCDD/F formation on model fly ashes. Chemosphere 42: 797-802.

Wu, J.Z. and Hsu, Y.C. (2018). Decision analysis on entering the China pharmaceutical market: Perspectives from Taiwanese companies. Comput. Ind. Eng. 125: 751-763.

Wu, X., Huang, W., Zhang, Y., Zheng, C., Jiang, X., Gao, 
X. and Cen, K. (2015). Characteristics and uncertainty of industrial VOCs emissions in China. Aerosol Air Qual. Res. 15: 1045-1058.

Xu, S., Chen, T., Li, X., Yan, J. and Cen, K. (2018). Behavior of PCDD/Fs, PCBS, CBZS and PAHS during thermal treatment of various fly ash from steel industry. Aerosol Air Qual. Res. 18: 1008-1018.

Yoon, Y.W., Jeon, T.W., Son, J.I., Kim, K.Y., Kwon, E.H., Shin, S.K. and Kang, J.G. (2017). Characteristics of PCDDs/PCDFs in stack gas from medical waste incinerators. Chemosphere 188: 478-485.

Zhan, M., Wang, T., Yang, J., Ji, L., Zhou, G., Chen, T., Li, $X$. and Lin, X. (2018). The Behaviors and Relationships of PCDD/Fs and Chlorobenzenes in the Whole Process of one Municipal Solid Waste Incinerator. Aerosol Air Qual. Res. 18: 3134-3146.

Zhao, Y., Zhan, J., Liu, G., Zheng, M., Jin, R., Yang, L., Hao, L., Wu, X., Zhang, X. and Wang, P. (2017).
Evaluation of dioxins and dioxin-like compounds from a cement plant using carbide slag from chlor-alkali industry as the major raw material. J. Hazard. Mater. 330: 135-141.

Zhu, F., Li, X., Lu, J.W., Hai, J., Zhang, J., Xie, B. and Hong, C. (2018). Emission characteristics of PCDD/Fs in stack gas from municipal solid waste incineration plants in Northern China. Chemosphere 200: 23-29.

Zou, L., Ni, Y., Gao, Y., Tang, F., Jin, J. and Chen, J. (2018). Spatial variation of PCDD/F and PCB emissions and their composition profiles in stack flue gas from the typical cement plants in China. Chemosphere 195: 491497.
Received for review, June 3, 2019 Revised, August 20, 2019 Accepted, August 26, 2019 